\title{
The knowledge, attitudes and practices of doctors, pharmacists and nurses on antimicrobials, antimicrobial resistance and antimicrobial stewardship in South Africa
}

\begin{tabular}{|c|c|}
\hline \multicolumn{2}{|c|}{$\begin{array}{l}\text { Authors: } \\
\text { Reshma Balliram }{ }^{1} \\
\text { Wilbert Sibanda } \\
\text { Sabiha Y. Essack }\end{array}$} \\
\hline \multicolumn{2}{|c|}{$\begin{array}{l}\text { Affiliations: } \\
{ }^{1} \text { Antimicrobial Research Unit, } \\
\text { Faculty of Health Sciences, } \\
\text { University of KwaZulu-Natal, } \\
\text { Durban, South Africa }\end{array}$} \\
\hline \multicolumn{2}{|c|}{$\begin{array}{l}{ }^{2} \text { Department of Public } \\
\text { Health, Faculty of Health } \\
\text { Sciences, University of } \\
\text { KwaZulu-Natal, Durban, } \\
\text { South Africa }\end{array}$} \\
\hline \multicolumn{2}{|c|}{$\begin{array}{l}\text { Corresponding author: } \\
\text { Sabiha Essack, } \\
\text { essacks@ukzn.ac.za }\end{array}$} \\
\hline \multicolumn{2}{|c|}{$\begin{array}{l}\text { Dates: } \\
\text { Received: } 05 \text { Nov. } 2020 \\
\text { Accepted: } 09 \text { Feb. } 2021 \\
\text { Published: } 21 \text { Apr. } 2021\end{array}$} \\
\hline \multicolumn{2}{|c|}{$\begin{array}{l}\text { How to cite this article: } \\
\text { Balliram R, Sibanda W, } \\
\text { Essack SY. The knowledge, } \\
\text { attitudes and practices of } \\
\text { doctors, pharmacists and } \\
\text { nurses on antimicrobials, } \\
\text { antimicrobial resistance and } \\
\text { antimicrobial stewardship in } \\
\text { South Africa. S Afr J Infect } \\
\text { Dis. 2021;36(1), a262. } \\
\text { https://doi.org/10.4102/ } \\
\text { sajid.v36i1.262 }\end{array}$} \\
\hline \multicolumn{2}{|c|}{$\begin{array}{l}\text { Copyright: } \\
\text { (C) 2021. The Authors. } \\
\text { Licensee: AOSIS. This work } \\
\text { is licensed under the } \\
\text { Creative Commons } \\
\text { Attribution License. }\end{array}$} \\
\hline \multicolumn{2}{|l|}{ Read online: } \\
\hline arpar & $\begin{array}{l}\text { Scan this QR } \\
\text { code with your } \\
\text { smart phone or } \\
\text { mobile device } \\
\text { to read online. }\end{array}$ \\
\hline
\end{tabular}

Background: Sustained injudicious and indiscriminate use of antimicrobials has exerted selection pressure for developing antimicrobial resistance (AMR), requiring behaviour change from healthcare professionals (HCPs) based on their knowledge, attitudes and practices (KAP) on antimicrobials, AMR and antimicrobial stewardship (AMS).

Methods: A cross-sectional online questionnaire-based survey was conducted nationally amongst doctors, pharmacists and nurses from November 2017 to January 2018. The questionnaire comprised demographic information and KAP questions.

Results: Respondents comprised of 1120 doctors, 744 pharmacists and 659 nurses. Antimicrobial resistance was considered a severe problem globally and nationally by majority of HCPs. Self-assessment of knowledge revealed gaps in understanding of antimicrobials, AMR and AMS. Confidence scores in prescribing by doctors, pharmacists and nurses were $57.82 \%, 32.88 \%$ and $45.28 \%$, respectively. Doctors, 441 (45.2\%) indicated no confidence in using combination therapy. Prescribing correctly showed a confidence level of 33.99\% from 436 doctors, $41.88 \%$ from nine pharmacists and 35.23\% from 107 nurses. Healthcare professionals (1600 [91.22\%]) stated educational campaigns would combat AMR. Only $842(40.13 \%)$ HCPs attended training on these topics and 1712 (81.60\%) requesting more education and training.

Conclusion: This is the first comparative survey on KAP of practising doctors, pharmacists and nurses in South Africa. Doctors had the highest knowledge score followed by nurses and pharmacists. Practice scores did not corroborate knowledge and the higher attitude scores. Gaps in KAP were evident. Healthcare professionals indicated the need for more education and training, thus requiring a review of pre-service and in-service education and training in addition to continued professional development programmes for practising HCPs.

Keywords: antimicrobials; antimicrobial resistance; antimicrobial stewardship; knowledge; attitudes; practices.

\section{Introduction}

The injudicious and irrational use of antimicrobials, vis-à-vis, incorrect clinical indication, dosing and administration, and, non-complaince of patients have been implicated in the development of antimicrobial resistance (AMR). ${ }^{1}$ Antimicrobial resistance, an escalating threat globally, is of concern in human and animal health, the food industry and agriculture. ${ }^{2}$ It adversely affects treatment, increases morbidity and mortality, results in extended hospital stays and necessitates more expensive, and often more toxic, treatment options. ${ }^{3}$ According to best available data, an estimated 700000 people worldwide die of resistant bacterial infections a year, and it is estimated that this may increase to 10 million people dying a year at a cost of 100 trillion USD by $2050 .{ }^{4}$ Change lies in the hands of healthcare professionals (HCPs) responsible for the prescription, dispensing and administration of antimicrobial medicines to patients, namely doctors, pharmacists and nurses, respectively.

The Global Action Plan (GAP) on AMR addresses AMR through five strategic objectives. Of these, strategic objective 1 is increased awareness of AMR through effective communication, education and training. 
This would be achieved by each member state implementing interventions to: (1) increase national awareness of AMR via programmes that target the different audiences in human health, animal health and the environment, (2) incorporate AMR as a core component in professional education, training and certification, (3) incorporate antimicrobial use and resistance into the school syllabus to improve understanding and further awareness with all information being accurate and relevant, (4) prioritise AMR as an important health issue requiring urgent action from all governmental departments and (5) create a multisectoral committee to address AMR from a One Health perspective. ${ }^{2}$ Education for all HCPs on antimicrobial prescribing needs to begin at undergraduate levels, and should continue in post-graduation with specific training in using treatment guidelines. ${ }^{5}$ The range of antimicrobial prescribers has been changing, with legislation allowing nurses, pharmacists and emergency care personnel to prescribe antimicrobials under certain conditions in South Africa (SA). ${ }^{6,78}$ Healthcare professionals are responsible for managing antimicrobials, namely prescribing, dispensing and administering antimicrobials to patients. They must be knowledgeable and up-to-date on issues related to antimicrobials, AMR and antimicrobial stewardship (AMS). This study therefore ascertained the knowledge, attitudes and practices (KAP) of doctors, pharmacists and nurses in order to identify gaps for educational intervention.

\section{Methods \\ Study design and population}

A descriptive cross-sectional online survey was conducted nationally. Study sample included $15 \quad 111$ (40.77\%) pharmacists, including community-service pharmacists registered with the South African Pharmacy Council (SAPC). There were also 16260 (43.87\%) doctors and 5695 (15.36\%) nurses, comprising of 5630 registered nurses and 65 enrolled nurses, who subscribed to Medpages, an SA database with contact information of HCPs in SA. The SAPC provided contact information of pharmacists and community-service pharmacists to the principal investigator, which was used to email the survey questionnaires. Medpages distributed the survey questionnaire to all doctors and nurses on their database. The study was undertaken from November 2017 to January 2018.

\section{Survey instrument}

The data were collected using a self-administered, web-based questionnaire with voluntary informed consent.

Questionnaire (Appendix 1) was adapted and piloted from a combination of questionnaires already available in literature. ${ }^{9,10,11,12}$ Responses were anonymous. Questionnaire was divided into four sections and consisted of open-ended, closed-ended (yes or no) and Likert style questions (one of the following options: strongly agree, agree, neutral, disagree, strongly disagree).
The first section collected demographic, academic and professional data of the participants.

Second section consisted of questions that assessed the participants' knowledge on antimicrobials, AMR and stewardship, contributing factors to AMR, sources of information and confidence in prescribing antimicrobials. Third section evaluated the participants' attitudes and beliefs on antimicrobials, AMR and their contribution to AMR. Final section was practice-related and involved antimicrobial sensitivity-testing, empiric-prescribing, use of standard treatment guidelines (STGs), advice imparted to patients and prescribing for diagnosed medical conditions.

\section{Statistical analysis}

Dataset was analysed using IBM Statistical Package for the Social Sciences (IBM SPSS) version 25 (IBM Corp. Released 2018. IBM SPSS Statistics for Windows, Version 25.0. Armonk, NY: IBM Corp) using simple descriptive statistics to create frequencies and percentages. Continuous variables, such as ages, were described as mean \pm standard deviation or median and compared using the Student's $t$-test or Wilcoxon test as appropriate. Categorical variables, such as groups, were described as proportions and compared using Chi-square test or Fisher's exact test as appropriate. The analysis of variance (ANOVA) statistical test was used to compare the $\mathrm{KAP}$ scores between the three professions, and the Bonferroni post-hoc test further described the pairwise statistically significant difference between the professions. For each factual question, a mark was allocated when the answer was correct. Other questions were assessed and given a mark for the most appropriate correct response. Responses for 'strongly agree' and 'agree' were combined as well as for 'disagree' and 'strongly disagree'. The study population had declined from Section 1-4 of the questionnaire, thus completed sections were analysed separately. Partially completed questionnaires were also considered, hence the different ' $n$ ' values per section. The South African STGs were used to assess doctors and nurses' choices of antimicrobial treatment for given medical conditions and the primary care drug treatment (PCDT) list was used to assess pharmacists' choice of antimicrobial treatment in Section 4 of the questionnaire.

\section{Ethical considerations}

Ethical approval was obtained from the Humanities and Social Sciences Research Ethics Committee of University of KwaZulu-Natal (HSS/0868/017M) prior to the study.

\section{Results}

Total number of respondents in this study was 2523 (6.81\%) HCPs, consisting of 1120 doctors, 744 pharmacists and 659 nurses with response rates of $6.89 \%, 4.92 \%$ and $11.57 \%$, respectively. There were $1520(60.25 \%)$ females and 1003 
$(39.75 \%)$ males. The modal-age groups were $31-40$ years (30.71\%) for doctors, $21-30$ years (30.24\%) for pharmacists and 51-60 years (36.87\%) for nurses. Amongst nurses, 392 (59.48\%) possessed a diploma qualification. A greater proportion of HCPs, that is 1843 (73.05\%), occupied jobs in urban areas whilst the number for those in rural areas was 306 (12.13\%). Most HCPs, 1205 (47.76\%), worked in private practice and $792(31.39 \%)$ worked in public (Appendix 1).

\section{Knowledge}

\section{Awareness of antimicrobial resistance}

The majority of HCPs (93.37\%) perceived AMR to be a serious problem globally (Table 1). Using a one-way ANOVA, there were statistically significant differences in the appreciation of the problem of AMR between the different professions ( $p=0.002)$ with nurses being least aware. Similar numbers of HCPs agreed it was a national problem. However, much lower number of HCPs $(73.77 \%)$ agreed AMR was a serious problem in their hospital or practice and there was a statistically significant difference between them $(p=0.011)$.

\section{Assessment of knowledge on antimicrobials, antimicrobial resistance and antimicrobial stewardship}

The self-assessment of knowledge indicated that 791 (37.70\%) HCPs were $75 \%$ confident of their knowledge on all three topics with 349 (16.6\%) HCPs showing 100\% confidence (Figure 1). Notably, a greater percentage of nurses $(52.40 \%$; 261) had $\leq 50 \%$ confidence levels on knowledge of all three topics as compared to pharmacists $(45.3 \% ; 283)$ and doctors (39.3\%; 383). Using the ANOVA test, there were statistically significant differences in confidence levels of knowledge on antimicrobials, AMR and AMS between doctors, pharmacists and nurses ( $p=0.0001,0.00001$ and 0.009 , respectively). A Bonferroni post-hoc test indicated that doctors were different from nurses and pharmacists were different from nurses, however doctors and pharmacists were not statistically different.

Varying numbers of HCPs correctly stated antimicrobials were not effective in treating acute viral infections $(p=0.000)$, and a majority of HCPs correctly stated common colds are caused by viruses (Table 1).

\section{Contributory factors towards antimicrobial resistance}

Healthcare professionals identified the overuse of antimicrobials by prescriptions (1922; 91.61\%), patient pressure for antimicrobial prescriptions (1579; 75.26\%) and non-adherence of patients to prescribed treatment (1537; 73.26\%) as most contributory towards AMR, as depicted in Figure 2. The least contributory was the lack of immunisation campaigns $(262 ; 12.49 \%)$. Statistically significant differences $(p<0.05)$ were noted between the three groups of HCPs in seven of the nine contributing factors.

\section{Confidence in prescribing antimicrobials}

Self-assessment on confidence in 10 aspects of prescribing antimicrobials showed 587 (60.21\%) doctors were confident in $7(70 \%)$ aspects. No confidence was reported by 433 $(44.40 \%)$ doctors about using combination therapy when

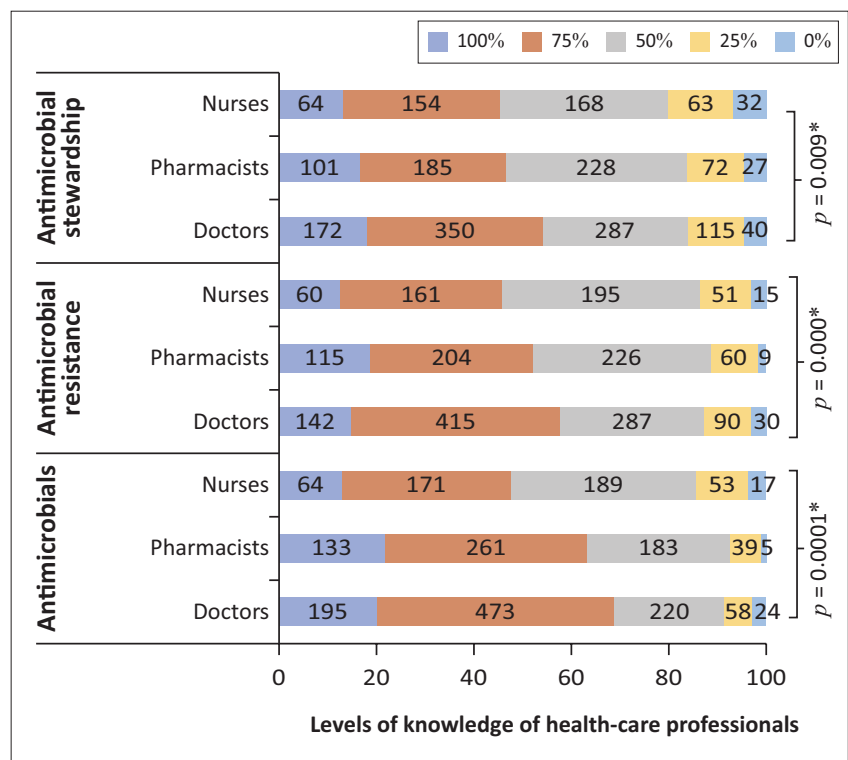

Note: Nurses: $n=498$; Pharmacists: $n=625$; Doctors: $n=975$.

*, Chi-square test.

FIGURE 1: Healthcare professionals' self-assessment of their levels of confidence on knowledge of antimicrobials, antimicrobial resistance and antimicrobial stewardship.

TABLE 1: Healthcare professionals' responses on awareness, knowledge and education on antimicrobials, antimicrobial resistance and antimicrobial stewardship.

\begin{tabular}{|c|c|c|c|c|c|c|c|}
\hline \multirow[t]{2}{*}{ Variable } & \multicolumn{2}{|c|}{ Doctors } & \multicolumn{2}{|c|}{ Pharmacists } & \multicolumn{2}{|c|}{ Nurses } & \multirow[t]{2}{*}{$p$ (ANOVA) } \\
\hline & $n$ & $\%$ & $n$ & $\%$ & $n$ & $\%$ & \\
\hline \multicolumn{8}{|l|}{ AMR is a serious problem: } \\
\hline Globally & 940 & 96.4 & 594 & 95.0 & 445 & 88.7 & 0.002 \\
\hline Nationally & 942 & 96.6 & 599 & 95.8 & 402 & 92.8 & - \\
\hline In your hospital or practice & 761 & 78.1 & 475 & 76.0 & 335 & 67.2 & 0.011 \\
\hline $\begin{array}{l}\text { Antimicrobials are not effective in treating acute } \\
\text { viral infections - True }\end{array}$ & 925 & 94.9 & 579 & 92.6 & 375 & 75.3 & 0.000 \\
\hline Common colds are caused by viruses - True & 966 & 99.1 & 608 & 97.3 & 449 & 90.2 & 0.000 \\
\hline $\begin{array}{l}\text { Attended workshops and training on either or } \\
\text { both AMS and antimicrobials }\end{array}$ & 435 & 44.6 & 242 & 38.7 & 165 & 33.1 & 0.001 \\
\hline $\begin{array}{l}\text { Wanted more education and training on AMR, } \\
\text { AMS and antimicrobial use }\end{array}$ & 789 & 80.1 & 495 & 79.2 & 428 & 85.9 & 0.000 \\
\hline
\end{tabular}

Note: Nurses: $N=498$; Pharmacists: $N=625$; Doctors: $N=975$.

AMR, antimicrobial resistance; AMS, antimicrobial stewardship. 


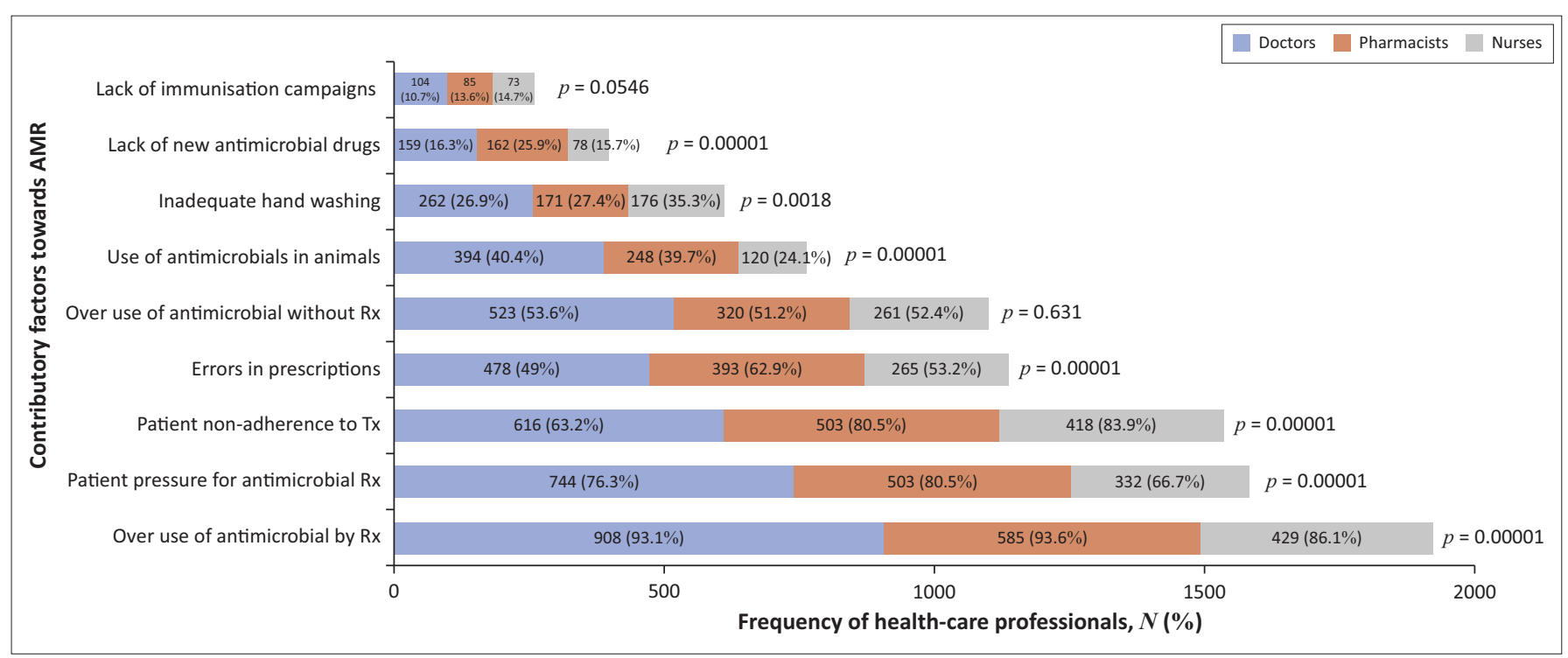

Note: Doctors: $N=975$; Pharmacists: $N=625$; Nurses: $N=498$.

AMR, antimicrobial resistance.

FIGURE 2: Selection of contributory factors resulting in antimicrobial resistance.

TABLE 2: Self-assessment on confidence in various aspects of prescribing antimicrobials.

\begin{tabular}{|c|c|c|c|c|c|c|c|}
\hline \multirow[t]{2}{*}{ Levels of confidence $\dagger$} & \multirow[t]{2}{*}{ Variable } & \multicolumn{2}{|c|}{ Confident } & \multicolumn{2}{|c|}{ Unconfident } & \multirow{2}{*}{$\begin{array}{l}p \text {-Value } \\
\text { (ANOVA) }\end{array}$} & \multirow{2}{*}{$\begin{array}{l}\text { Statistically significant differences } p<0.05 \\
\text { were observed in the following }\end{array}$} \\
\hline & & $n$ & $\%$ & $n$ & $\%$ & & \\
\hline \multirow{3}{*}{$\begin{array}{l}\text { Making an accurate diagnosis of } \\
\text { the infection }\end{array}$} & Doctors & 603 & 61.8 & 262 & 35.1 & \multirow[t]{3}{*}{0.000} & \multirow{3}{*}{$\begin{array}{l}\text { Between doctors and pharmacists }(p=0.00) \text {, } \\
\text { pharmacists and nurses }(p=0.00)\end{array}$} \\
\hline & Pharmacists & 154 & 24.7 & 166 & 26.6 & & \\
\hline & Nurses & 251 & 50.4 & 107 & 21.5 & & \\
\hline \multirow{3}{*}{$\begin{array}{l}\text { Decision not to prescribe antimicrobial } \\
\text { when patient has fever with no serious } \\
\text { criteria and you're not sure of diagnosis }\end{array}$} & Doctors & 505 & 51.8 & 439 & 45.0 & \multirow[t]{3}{*}{0.000} & \multirow{3}{*}{$\begin{array}{l}\text { Between doctors and nurses }(p=0.00) \\
\text { pharmacists and nurses }(p=0.001)\end{array}$} \\
\hline & Pharmacists & 180 & 28.8 & 136 & 21.8 & & \\
\hline & Nurses & 247 & 49.6 & 101 & 20.3 & & \\
\hline \multirow[t]{3}{*}{ Selecting the correct antimicrobial } & Doctors & 582 & 59.7 & 364 & 37.3 & \multirow[t]{3}{*}{0.024} & \multirow[t]{3}{*}{ Between pharmacists and nurses $(p=0.023)$} \\
\hline & Pharmacists & 213 & 34.1 & 152 & 24.3 & & \\
\hline & Nurses & 231 & 46.4 & 108 & 21.7 & & \\
\hline \multirow{3}{*}{$\begin{array}{l}\text { Selecting the correct dosage for } \\
\text { the antimicrobial }\end{array}$} & Doctors & 606 & 62.2 & 340 & 34.9 & \multirow[t]{3}{*}{0.005} & \multirow[t]{3}{*}{ Between doctors and nurses $(p=0.008)$} \\
\hline & Pharmacists & 276 & 44.2 & 119 & 19.1 & & \\
\hline & Nurses & 248 & 49.8 & 89 & 17.9 & & \\
\hline \multirow{2}{*}{$\begin{array}{l}\text { Selecting the correct interval for } \\
\text { the antimicrobial }\end{array}$} & Doctors & 593 & 60.8 & 353 & 36.2 & \multirow[t]{2}{*}{0.13} & \multirow[t]{2}{*}{ Between doctors and nurses $(p=0.018)$} \\
\hline & Nurses & 241 & 48.4 & 97 & 19.5 & & \\
\hline \multirow{3}{*}{$\begin{array}{l}\text { Selecting the correct duration for } \\
\text { the antimicrobial }\end{array}$} & Doctors & 578 & 59.3 & 367 & 37.6 & \multirow[t]{3}{*}{0.003} & \multirow[t]{3}{*}{ Between doctors and nurses $(p=0.002)$} \\
\hline & Pharmacists & 258 & 41.5 & 137 & 21.9 & & \\
\hline & Nurses & 244 & 48.8 & 97 & 19.5 & & \\
\hline \multirow[t]{3}{*}{ Using combination therapy if necessary } & Doctors & 501 & 51.3 & 441 & 45.2 & \multirow[t]{3}{*}{0.447} & \multirow{3}{*}{$\begin{array}{l}\text { No significant differences were observed, } \\
p>0.05\end{array}$} \\
\hline & Pharmacists & 200 & 32.0 & 188 & 30.1 & & \\
\hline & Nurses & 192 & 38.6 & 146 & 29.3 & & \\
\hline \multirow{3}{*}{$\begin{array}{l}\text { Interpreting microbiological } \\
\text { laboratory results }\end{array}$} & Doctors & 589 & 60.4 & 354 & 36.3 & \multirow[t]{3}{*}{0.000} & Between doctors and pharmacists $(p=0.00)$, \\
\hline & Pharmacists & 186 & 29.8 & 198 & 31.7 & & \\
\hline & Nurses & 220 & 44.2 & 142 & 28.5 & & \\
\hline When to stop/streamline the & Doctors & 524 & 53.7 & 419 & 43.0 & 0.000 & Between doctors and pharmacists $(p=0.00)$, \\
\hline $\begin{array}{l}\text { antimicrobal therapy according to } \\
\text { clinical evaluations and investigations }\end{array}$ & Pharmacists & 153 & 24.5 & 210 & 33.6 & & \\
\hline & Nurses & 195 & 39.2 & 150 & 30.1 & & \\
\hline Selecting between an intravenous or & Doctors & 557 & 57.1 & 386 & 39.6 & 0.000 & Between doctors and pharmacists $(p=0.00)$, \\
\hline & Pharmacists & 165 & 26.4 & 190 & 30.4 & & pramacists ana nurses ( $p=0.018$ ) \\
\hline
\end{tabular}

Note: Nurses: $N=498$; Pharmacists: $N=625$; Doctors: $N=975$.

$\uparrow$, Prescribing antimicrobials represented as a percentage.

ANNOVA, analysis of variance.

necessary, about when to stop or streamline therapy according to clinical evaluations and investigations and about making decision not to prescribe antimicrobials when there's fever with no serious criteria (Table 2). A total of 244
(48.93\%) nurses stated confidence in six (60\%) aspects, and overall $117(23.50 \%)$ nurses stated no confidence in prescribing antimicrobials. Only 206 (33.88\%) pharmacists were confident in all aspects of prescribing with 156 (25\%) stating no 
confidence when prescribing antimicrobials. The confidence level of pharmacists and nurses can be gauged from the fact that $221(35.38 \%)$ pharmacists and 116 (23.44\%) nurses selected 'not applicable' to prescribing antimicrobials. Statistically significant differences $(p<0.05)$ were noted between the three groups of HCPs in eight aspects of prescribing.

The most preferred sources of information on appropriate use of antimicrobials for doctors were STGs (706; 72.5\%) followed by South African Medicines Formulary (SAMF) (579; 59.4\%). The pharmacists preferred the SAMF (453; $72.5 \%)$ and STGs $(426 ; 68.2 \%)$, whilst nurses used STGs (343; $68.9 \%$ ) and indicated equal usage of the SAMF and WHO guidelines (277; 55.6\%).

A majority (1972; 93.99\%) of HCPs agreed that there were risks associated with the irrational use of antimicrobials, most noted risks being AMR $(1729 ; 82.41 \%)$, side effects $(675$; $32.17 \%$ ) and adverse drug reactions (486; $23.16 \%$ ). Only 842 (40.13\%) HCPs had attended any workshops or training on antimicrobials and AMS.

A total of 1712 (81.60\%) HCPs requested more education and training on antimicrobial use, AMR and AMS.

There was a statistically significant difference in total knowledge of antimicrobials, AMR and AMS between the three groups of HCPs. Using the Bonferroni post-hoc tests, it was observed that doctors scored significantly higher than both the pharmacists and nurses $(p<0.05)$, with the knowledge scores being $65.74 \%, 60.07 \%$ and $60.14 \%$, respectively.

\section{Attitudes}

Doctors $(551 ; 64.1 \%)$, pharmacists $(354 ; 68.7 \%)$ and nurses $(249 ; 65.5 \%)$ disagreed that antimicrobials were safe drugs that could be commonly prescribed. Majority $(1689 ; 96.29 \%)$ agreed that prescribing antimicrobials to patients who did not really need them, would ultimately have a negative impact on their health.

\section{Strategies to combat antimicrobial resistance}

The most important strategies the HCPs believed would aid in combatting AMR were educational campaigns (1600; $91.22 \%)$, use of therapeutic guidelines (1486; 84.72\%) and improved infection control (1163; 66.31\%). Vaccination campaigns $(543 ; 30.96 \%)$ were surprisingly reported to be least important. Statistically significant differences $(p<0.05)$ were observed for two strategies (Figure 3).

Varying numbers of HCPs - 600 (69.8\%) doctors, 414 (80.4\%) pharmacists and $323(85.0 \%)$ nurses - believed skipping or missing a dose or two of antimicrobials contributed to the development of AMR and this difference was statistically significant $(p=0.000)$. A total of $545(63.4 \%)$ doctors, 221 (42.9\%) pharmacists and 126 (33.2\%) nurses believed they personally contributed towards AMR in some form $(p=0.000)$.

With respect to attitude towards antimicrobials, AMR and AMS, using a one-way ANOVA, there was a statistically significant difference between doctors, pharmacists and nurses with attitude scores of $68.71 \%, 68.59 \%$ and $65.94 \%$, respectively $(p=0.013)$. Using the Bonferroni post-hoc analysis, doctors and pharmacists scored statistically higher than nurses $(p=0.014)$.

\section{Practices}

\section{Prescribing antimicrobials}

Only 22 (4.43\%) pharmacists possessed Section 22A (15) permit, which allowed them to prescribe for PCDT, of which only 16 (3.22\%) pharmacists prescribed antimicrobial drugs. Almost a third of nurses $(126 ; 34.00 \%)$ possessed the concession permit in terms of Section 22A (12) of the Medicines and Substances Control Act of 1965 and Section 38A of the

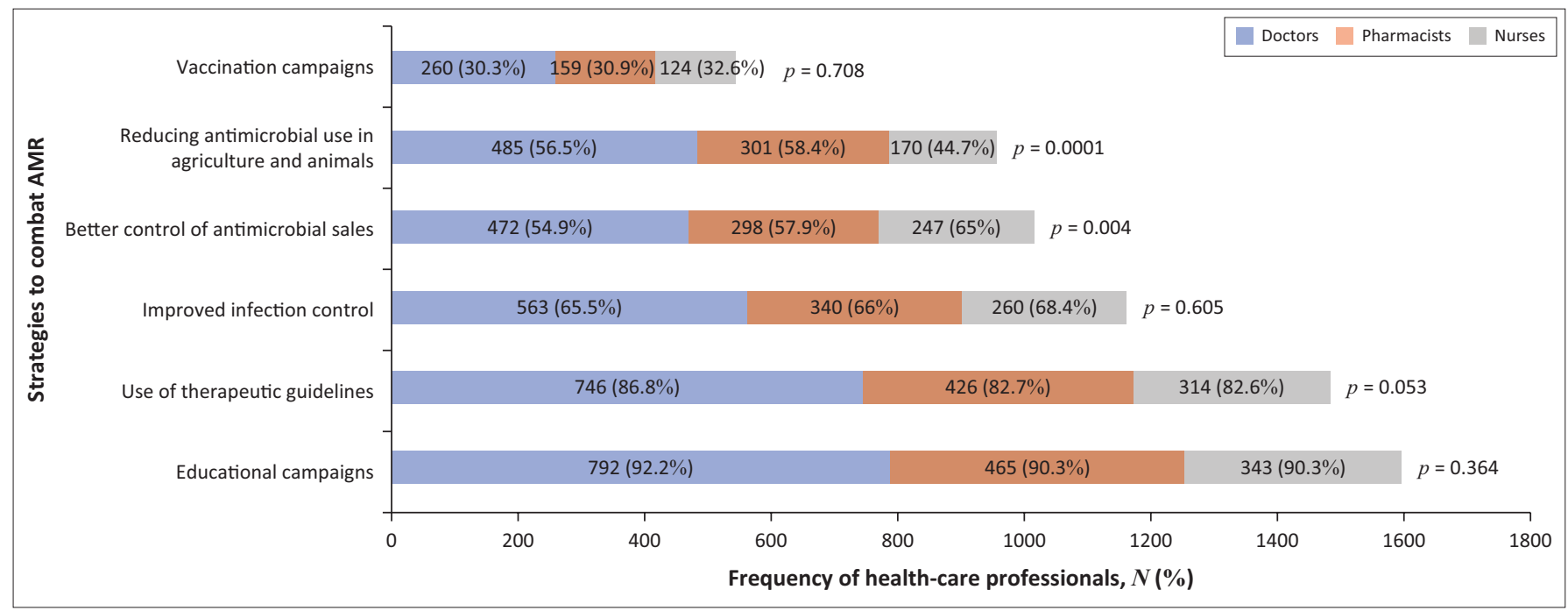

Note: Nurses: $n=380$; Pharmacists: $n=515$; Doctors: $n=859$.

AMR, antimicrobial resistance.

FIGURE 3: Attitudes on strategies that would combat antimicrobial resistance. 
Nursing Act of 1978, which allowed nurses to prescribe medicines. However, only 75 (20.22\%) prescribed antimicrobial drugs. In this study, $82(16.50 \%)$ pharmacists and $33(8.89 \%)$ nurses prescribed antimicrobials without a licence. Majority of antimicrobials were prescribed by doctors.

\section{Antimicrobial stewardship}

Six hundred and seventy-eight (80.52\%) doctors, 19 (3.82\%) pharmacists and $61(16.44 \%)$ nurses prescribed antimicrobials empirically $(p=0.000)$. Four hundred and forty-one $(52.38 \%)$ doctors, seven (1.41\%) pharmacists and 83 (22.37\%) nurses sent samples for microbiology testing before initiating antimicrobials. Only 496 (58.90\%) doctors, 349 (70.22\%) pharmacists and $185(49.87 \%)$ nurses possessed the latest South African STGs $(p=0.000)$. However, only 197 (23.40\%) doctors, 42 (8.45\%) pharmacists and 66 (17.79\%) nurses always used the STGs $(p=0.000)$.

Advice imparted to patients on antimicrobial use is reported in Figure 4. On the safe use of antimicrobials, 309 (83.29\%) nurses gave the most correct advice, followed by $404(81.29 \%)$ pharmacists and $630(74.82 \%)$ doctors $(p<0.00)$.

Based on a range of practice scores, between 0 (poor) and 100 (best practice), average scores for doctors, pharmacists and nurses were $57.68 \% \pm 16.42 \%, 43.14 \% \pm 16.53 \%$ and $54 \% \pm$ $14.34 \%$, respectively. Using an ANOVA test, practice scores for the three groups of HCPs were statistically significantly different $(p<0.05)$.

\section{Selection of appropriate antimicrobial treatment}

There was a higher percentage of appropriate treatment (41.88\%) provided by nine pharmacists compared to $33.99 \%$ from 436 doctors and 35.23\% from 107 nurses. However, there were fewer pharmacists who were eligible to provide treatment for the given conditions. It must be noted only $1.87 \%$ of nurses provided the correct strength, interval and duration for treatment.

\section{Discussion}

To our knowledge, this is the largest national study ascertaining KAP on antimicrobials, AMR and AMS amongst prescribers, dispensers and administrators of antimicrobial medicines to patients. This is the first KAP study amongst doctors, pharmacists and nurses in SA using the same tool and it provides valuable insights and information on strengths and weaknesses of KAP amongst HCPs and indicates areas where interventions are required.

Antimicrobial resistance is an increasingly serious public health threat. ${ }^{13}$ Awareness of AMR is the first step in addressing and reducing this global problem. ${ }^{2}$ We found that majority of HCPs in SA have been sensitised to AMR as a national and global concern, with doctors having most awareness followed by pharmacists and then nurses who had the least conceptual awareness. However, as a group, HCPs' awareness of AMR was comparable to a study by Burger et al. (2016), in which final year pharmacy students in SA reported $97.7 \%$ awareness to AMR as a global problem. ${ }^{14}$ Our HCPs' national awareness of AMR was similar to the studies by Vaillant et al. (2019), where French HCPs reported 93\% national awareness of AMR, and Farley et al. (2018), where $95.8 \%$ of primary care prescribers in SA stated AMR was a national problem..$^{15,16}$

The appreciation of the problem of AMR in context of their own work showed there was a much lower awareness of AMR in their hospitals or practices. This being stated, our findings showed higher awareness at practice level compared to the study by Vaillant et al. (2019), who reported 51.5\% of French HCPs had awareness of AMR at practice level. ${ }^{15}$

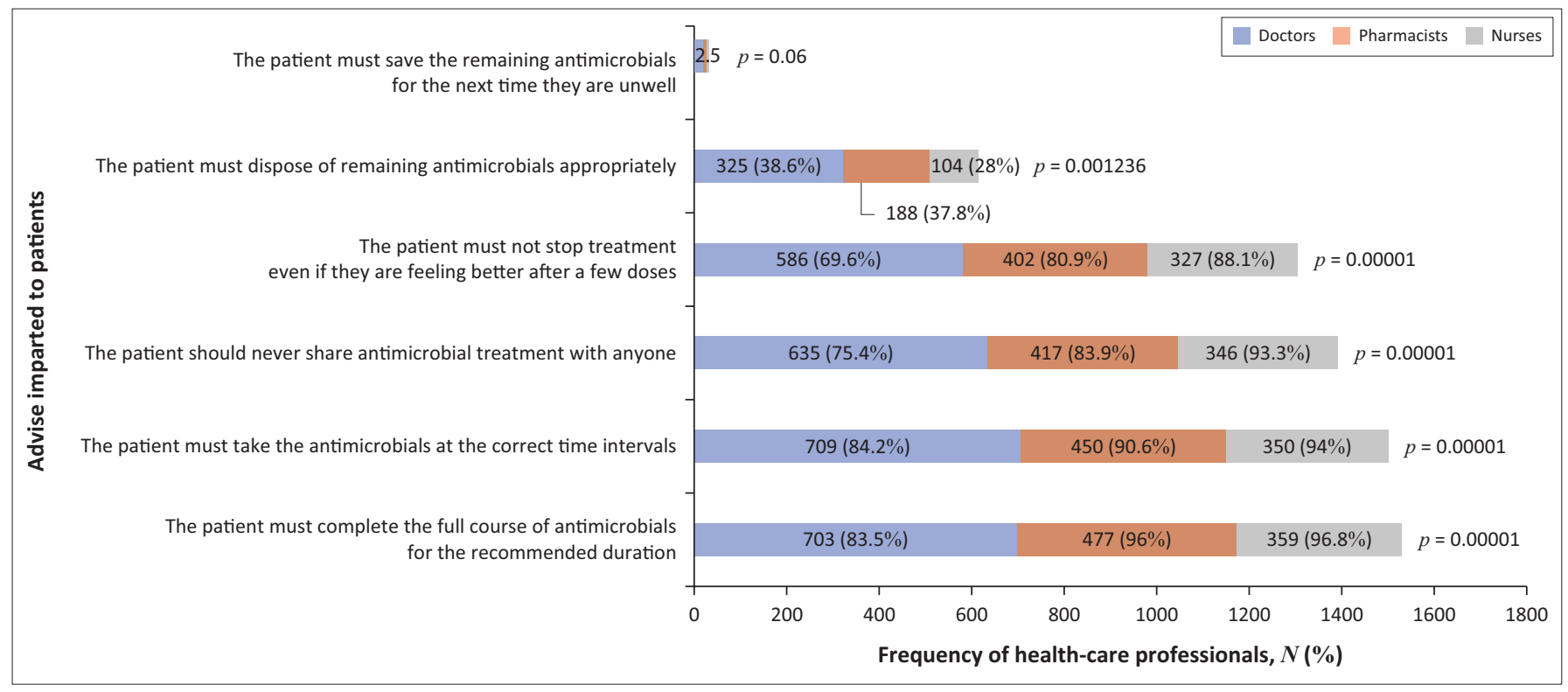

Note: Doctors: $n=842$; Pharmacists: $n=497$; Nurses: $n=371$.

FIGURE 4: Advice imparted by healthcare professionals to patients on antimicrobial use. 
Our research findings with respect to AMR awareness amongst HCPs are similar to Wasserman et al. (2017), who reported that $87 \%$ of final year medical students in SA agreed AMR was a global problem and only $61 \%$ saw it as a problem in their practice. ${ }^{17}$ Similar results were reported in other studies by Pulcini et al. (2010), where there was 95\% national awareness with $63 \%$ local awareness for AMR by junior doctors, and Garcia et al. (2011), who reported 97\% global and national awareness with $73 \%$ local awareness by prescribing doctors. ${ }^{9} 18$ However, our local awareness results contrasted with the study by Salsgiver et al. (2018) where it was reported that majority (89\%) of prescribers in the United States agreed AMR was a problem at their hospitals and prescribers actively supported AMS programmes at all hospitals. ${ }^{19}$

Based on their self-assessment, only $16.6 \%$ of HCPs were $100 \%$ confident in their knowledge of antimicrobials, AMR and AMS. The percentage of HCPs that had $75 \%$ confidence in their knowledge of antimicrobials and AMR, respectively, was $43 \%$ and $37 \%$. This is in contrast to the report by Dall (2019) whereby $80 \%$ of HCPs from 30 European countries stated they possessed sufficient knowledge on correct antimicrobial use and $96 \%$ stated having knowledge of AMR. ${ }^{20}$ Several aspects must be comprehensively considered when prescribing antimicrobials and complete confidence in each aspect is essential in achieving positive patient outcomes. In this study, diminished levels of confidence in the 10 aspects of prescribing antimicrobials were observed, with 587 (60.21\%) doctors confident in only seven aspects. A third of pharmacists stated confidence in all aspects whilst almost a quarter of the nurses were not confident in prescribing. Wasserman et al. (2017) reported that only a third of the students were confident in prescribing. ${ }^{17}$ Our results are also similar to findings by Pulcini et al. (2010), where it was found junior doctors in France and Scotland shared similar overall confidence $(57.61 \%)$ in prescribing antimicrobials to that of our doctors $(57.82 \%){ }^{9}$

Forty per cent of HCPs had attended or received training on antimicrobials and AMS with majority (81.61\%) indicating a need for more education and training. Our research findings are similar to those reported by Burger et al. (2016) whereby only $37.75 \%$ of pharmacy students had training on AMS and $90 \%$ needed more training. ${ }^{14}$ This was confirmed by Farley et al. (2018) where numerous prescribers requested more education on appropriate antimicrobial use and in Wasserman et al. (2017) where medical students wanted more education to aid in antibiotic prescribing. ${ }^{16,17}$ On the safe use of antimicrobials, close to two-thirds of HCPs indicated an awareness that in general antimicrobials are safe, however continuous use without due regard can have undesired effects. Majority of HCPs indicated that there could be negative effects on patients if antimicrobials were unnecessarily prescribed. The latter finding was supported by Burger et al. (2016). ${ }^{14}$
Numerous contributing factors result in AMR. In this study, the leading causes identified by majority of HCPs were: over-prescription of antimicrobials, patients' nonadherence to treatment and patient pressure for antimicrobial treatment. Burger et al. (2016) similarly reported widespread and overuse of antimicrobials (94.2\%) and poor patient adherence to medication (89.5\%) as contributing to AMR. ${ }^{14} \mathrm{~A}$ similar observation was made by Wasserman et al. (2017), who reported inappropriate use of antimicrobials ( $>95 \%$ ) as the primary cause of AMR. ${ }^{17}$. Similar findings were also reported in other studies by Pulcini et al. (2010) in France and Scotland, where $>90 \%$ of the junior doctors selected over-prescription of antimicrobials as being causative; Abera et al. (2014) in Ethiopia, where the nurse prescribers and doctors stated poor patient adherence $(86 \%)$ and overuse of antimicrobials $(80.5 \%)$ were responsible for AMR; and Dyar et al. (2014) in Europe, where final year medical students reported over-prescription of antimicrobials (>95\%) resulted in AMR..$^{9,10,21}$

According to our research, the most appropriate resources for antimicrobial selections were STGs, SAMF and international guidelines, respectively. This is in contrast to Wasserman et al. (2017) who reported that medical textbooks $(87 \%)$, registrars $(85 \%)$ and consultants $(83 \%)$ were most common learning resources. ${ }^{17}$ The important strategies chosen for combatting AMR by majority of HCPs were educational campaigns (91.22\%) and usage of therapeutic guidelines $(84.72 \%)$. This finding was similar to Burger et al. (2016) who reported that education on antimicrobial therapy (92.3\%), antimicrobial usage policies $(86.9 \%)$ and development of treatment guidelines (86.2\%) would combat AMR. ${ }^{14}$ Interestingly only $60.2 \%$ of HCPs were in possession of the latest South African STGs and only $17.8 \%$ always used it.

Attitude scores amongst all professions were slightly higher than knowledge scores and practice scores were the lowest. The doctors and pharmacists indicated higher attitude scores than nurses. Doctors obtained the highest knowledge scores. Practice scores did not corroborate the self-proclaimed knowledge and attitude scores.

\section{Limitations}

Gatekeeper permission to contact the HCPs proved problematic. The Protection of Personal Information Act (POPI) precluded access to the databases of the Health Professions Council of SA. The SA Nursing Council and Forum of University Nursing Deans of SA could not assist. The survey was conducted from November 2017 to January 2018, which is a festive period in SA, resulted in reduced participation from professionals.

Participation was voluntary, and, combined with the above constraints; the response rate was relatively poor. 
The results should thus be extrapolated to the wider HCP community with caution. Not all the questionnaires were fully completed resulting in different ' $n$ ' values for different sections.

\section{Conclusion}

This is the first comparative survey on KAP of practising doctors, pharmacists and nurses in SA. Doctors had the highest knowledge score followed by nurses and pharmacists, respectively. Practice scores did not corroborate knowledge and the higher attitude scores.

Self-assessment of knowledge showed that marginally more than half $(<55 \%)$ of HCPs were $\geq 75 \%$ confident in their knowledge on these topics. Confidence on prescribing antimicrobials showed that $<60 \%$ of doctors were confident in prescribing antimicrobials, with the confidence level even further reduced for pharmacists and nurses. Confidence in prescribing the correct treatment for given conditions ranged between $34 \%$ and $42 \%$ for the HCPs. Gaps in KAP were thus evident. Healthcare professionals indicated the need for more education and training, thus requiring a review of pre-service and in-service education and training in addition to CPD programmes for practising HCPs. It is recommended that both higher education institutions offering medical, pharmacy and nursing degrees as well as professional bodies regulating this education should map and update their existing curricula and scopes of practice, respectively, against the World Health Organization's competency framework and associated curriculum for healthcare workers' education and training on AMR.22

\section{Acknowledgements}

The authors would like to thank all the study participants, Mr K. Ngwenya for programming the questionnaire online and Ms C. Martin for scientific editing.

\section{Competing interests}

S.Y.E. is the chairperson of the Global Respiratory Infection Partnership and a member of the Global Hygiene Council, both sponsored by unrestricted educational grants from Reckitt and Benckiser (Pty.), United Kingdom. R.B. and R.S. do not have any conflicts of interest.

\section{Authors' contributions}

As the principal investigator, R.B. co-conceptualised the study, developed the protocol, undertook data collection and analysis and drafted the manuscript. As the sole supervisor of the Master's study, S.Y.E. co-conceptualised the study, guided the literature review and ethical clearance application, supervised data collection and analysis and undertook critical revision of the manuscript. The statistical analysis of the data was facilitated by W.S.

\section{Funding information}

This work was funded by the South African Research Chairs Initiative of the Department of Science and Technology and National Research Foundation of South Africa (Grant No. 98342) and the National Research Foundation Incentive Funding for Rated Researchers (Grant No. 85595). Ms Balliram further received a Master's Scholarship from the College of Health Sciences, University of KwaZulu-Natal.

\section{Data availability statement}

Raw data are available on request from the principle author.

\section{Disclaimer}

The views and opinions expressed in this article are those of the authors and do not necessarily reflect the official policy or position of any affiliated agency of the authors.

\section{References}

1. Duse AG. The global antibiotic resistance partnership. S Afr Med J [serial online] 2011 [cited 2016 Aug 28];101(8):551. Available from: www.samj.org.za/index. $\mathrm{php} / \mathrm{samj} /$ article/download/5068/3347

2. World Health Organisation. Global action plan on antimicrobial resistance [homepage on the Internet]. Geneva: WHO Press; 2015 [cited 2016 Apr 13] Available from: www.who.int/antimicrobial-resistance/global-action-plan/en/

3. World Health Organisation. Antimicrobial resistance [homepage on the Internet] 2016 [cited 2016 Nov 17]. Available from: www.who.int/mediacentre/factsheets/ fs194/en/

4. O'Neill J. Tackling drug-resistant infections globally: Final report and recommendations [homepage on the Internet]. 2016 [cited 2016 Dec 01] Available from: https://amr-review.org/sites/default/files/160525_Final\%20paper_ with\%20cover.pdf

5. Cooper C, Duguid M. Education and competency of prescribers. In: Antimicrobial stewardship in Australian hospitals [homepage on the Internet]. 2012 [cited 2016 Aug 21], part 1; p. 1-78. Available from: https://www.safetyandquality. gov.au/wp-content/uploads/2012/02/chapter6_education_competency_ prescribers.pdf

6. Health Professionals Council of South Africa. Medicines and Related Substances Act of 101 of 1965 [statute on the Internet]. 1965 [cited 2016 Aug 08]. Available from: https://www.hpcsa.co.za/Uploads/Legal/legislation/medicines_and_related_ sub_act_101_of_1965.pdf

7. Department of Health. Medicines and Related Substances Act, 1965 (Act 101 of 1965). Government Gazette [statute on the Internet]. 2012 [cited 2016 Aug 18], 13 Sep 2013; p. 11. Available from: https://www.hpcsa.co.za/Uploads/ ODO_2019/Announcements/Government_Gazette43051_R219_29Feb2020.pdf

8. South African Pharmacy Council. Scope of practice and qualification for authorised pharmacist prescriber. Government Gazette [statute on the Internet]. 2012 [cited 2016 Aug 18], 1 July 2011; p. 3-15. Available from: https://www.gov.za/sites/ default/files/gcis_document/201409/34428bn122.pdf

9. Pulcini C, Williams F, Molinari N, Davey P, Nathwani D. Junior doctors' knowledge and perceptions of antibiotic resistance and prescribing: A survey in France and Scotland. Clin Microbiol Infect Dis. 2011;17(1):80-87. https://doi.org/10.1111/ j.1469-0691.2010.03179.x

10. Abera B, Kibret M, Mulu W. Knowledge and beliefs on antimicrobial resistance among physicians and nurses in hospitals in Amhara Region, Ethiopia. BMC Pharmacol Toxicol. 2014;15(26). https://doi.org/10.1186/2050-6511-15-26

11. Fiol FDSD, Barberato-Filho S, Lopes LC, Bergamaschi CDC, Boscariol R. Assessment of Brazilian pharmacists' knowledge about antimicrobial resistance. J Infect Dev Ctries. 2015;9(3):239-243. https://doi.org/10.3855/jidc.4853

12. Sadasivam K, Chinnasami B, Ramraj B, Karthick N, Saravanan A. Knowledge, attitude and practice of paramedical staff towards antibiotic use and its resistance. Biomed Pharmacol J. 2016;9(1):337-343. https://doi.org/10.13005/ $\mathrm{bpj} / 944$

13. World Health Organisation. Antimicrobial resistance [homepage on the Internet]. Geneva; 2018 [cited 2018 Oct 15]. Available from: https://www.who.int/newsroom/fact-sheets/detail/antimicrobial-resistance

14. Burger M, Fourie J, Loots D, et al. Knowledge and perceptions of antimicrobial stewardship concepts among final year pharmacy students in pharmacy schools across South Africa. S Afr J Infect Dis. 2016;31(3):84-90. https://doi.org/10.1080/ 23120053.2016.1192808 
15. Vaillant L, Birgand G, Esposito-Farese M, et al. Awareness among French healthcare workers of the transmission of multidrug resistant organisms: A large cross-sectional survey. Antimicrob Resist Infect Control. 2019;8:173. https://doi. org/10.1186/s13756-019-0625-0

16. Farley E, Stewart A, Davies MA, Govind M, Van den Bergh D, Boyles TH. Antibiotic use and resistance: Knowledge, attitudes and perceptions among primary care prescribers in South Africa. S Afr Med J. 2018;108(9):763-767. https://doi. org/10.7196/SAMJ.2018.v108i9.12933

17. Wasserman S, Potgieter S, Shoul E, et al. South African medical students perceptions and knowledge about antibiotic resistance and appropriate prescribing: Are we providing adequate training to future prescribers? S Afr Med J. 2017;107(5):405-410. https://doi.org/10.7196/SAMJ.2017.v107i5.12370

18. Garcia C, Llamocca LP, Garcia K, et al. Knowledge, attitudes and practice survey about antimicrobial resistance and prescribing among physicians in a hospita Per. BMC Clin Pharmacol [serial online]. 2011 [cited 2016 May 17];11:18. Available from: http://www.biomedcentral.com/1472-6904/11/18
19. Salsgiver E, Bernstein D, Simon MS, et al. Knowledge, attitudes and practice regarding antimicrobial use and stewardship among prescribers at acute-care regarding antimicrobial use and stewardship among prescribers at acute-care org/10.1017/ice.2017.317

20. Dall C, CIDRAP News. Euro health workers spotty on antibiotic knowledge [homepage on the Internet]. 2019 [cited 2019 Nov 20]. Available from: http:// www.cidrap.umn.edu/news-perspective/2019/11/euro-health-workers-spottyantibiotic-knowledge

21. Dyar OJ, Pulcini C, Howard P, Nathwani D. European medical students: A first multicentre study of knowledge, attitudes and perceptions of antibiotic prescribing and antibiotic resistance. J Antimicrob Chemother. 2014;69:842-846. https://doi.org/10.1093/jac/dkt440

22. World Health Organisation. Competency framework for health workers' education and training on antimicrobial resistance. Geneva: World Health Organization; 2018. 


\section{Appendix 1}

The knowledge, attitudes and practices of doctors, pharmacists and nurses on antimicrobials, antimicrobial resistance and antimicrobial stewardship in South Africa.

\section{Informed consent to participate in a research study}

Dear Colleague,

We kindly request your participation in a national survey as a prescribing or dispensing health professional. The aim is to assess the knowledge, attitudes and practices (KAP) of doctors, pharmacists and nurses on antimicrobials, antimicrobial resistance (AMR) and antimicrobial stewardship (AMS) in South Africa (SA).

Antimicrobial resistance is a growing threat in both the developing and developed countries, causing problems in all spheres of human health, animal health, the food industry and agriculture.

Antimicrobials are substances of natural, semisynthetic or synthetic origin which kill or inhibit the growth of microorganisms whilst causing little to no harm or damage to the host. These include antibacterials, antivirals, antifungals and antiprotozoals.

Antimicrobial resistance occurs when the microorganisms withstand the antimicrobial agents which were initially effective in treating the infections caused by the microorganisms.

Antimicrobial stewardship is the coordinated programme which promotes the correct use of antimicrobials, improving patient outcomes, reducing AMR whilst decreasing the spread of infections caused by multidrug-resistant microorganisms.

The objectives of this study are as follows:

1. To assess the KAP of doctors, pharmacists and nurses on antimicrobials and AMR by means of a questionnaire survey.

2. To compare and contrast KAP within and between each profession.

3. To advise on education and training of these professions in terms of antimicrobials, AMR and AMS.

Your participation in this study involves answering questions about antimicrobials, AMR and AMS. The questions will be open-ended and close-ended and will take approximately $25 \mathrm{~min}$. Your participation is entirely voluntary.

Please be advised that:

- No identifying information will be stored or disseminated. Be assured that answers are anonymous as all surveys will be aggregated first before analysis.

- Confidentiality and anonymity is guaranteed by the electronic survey format.

- Your participation is critical for the success of this research study, and entirely voluntary. You are free to decline from participation.
- There are no known risks in participating in this study.

- This research study has been granted ethical clearance from the Humanities and Social Sciences Research Ethics Committee of University of KwaZulu-Natal (Approval No HSS/0868/017M).

- If you wish to proceed and participate after reading this letter, you are giving voluntary informed consent by proceeding with the survey.

Mariette Snyman, Administrator of Humanities and Social Sciences Research Ethics Committee Office, may be contacted on $+27(0) 31$ 2608350 or snymanm@ukzn.ac.za.

Thanking you in advance for your participation. If you have any questions or queries, please feel free to contact the following:

Researcher: Reshma Balliram, Bachelor of Pharmacy on 9502731@ stu.ukzn.ac.za.

Supervisor: Professor Sabiha Essack, South African Research Chair in Antibiotic Resistance \& One Health on $+27(0) 312607785$ or essacks@ukzn.ac.za.

We thank you in advance for your participation. Yours faithfully,

Reshma Balliram

There are 42 questions in this survey.

\section{Section 1: Demographical information}

What is your gender?

Please choose only one of the following:

Male $\bigcirc \quad$ Female $\mathrm{O}$

Which age group do you fall under?

Please choose only one of the following:

$\begin{array}{llllll}20-25 \text { years } & \bigcirc & 36-40 \text { years } & \bigcirc & 51-55 \text { years } & \bigcirc \\ 26-30 \text { years } & \bigcirc & 41-45 \text { years } & \bigcirc & 56-60 \text { years } & \bigcirc \\ 31-35 \text { years } & O & 46-50 \text { years } & \bigcirc & 60 \text { years }+ & \bigcirc\end{array}$

What is your race group?

Please choose only one of the following:

African $\mathrm{O}$

Indian

White 0

Coloured

Other

In what year did you graduate? 
At which University/College did you obtain your first degree or diploma?

What qualification did you obtain?

For doctors only:

MBChB (Bachelor of Medicine and Bachelor of Surgery)

Master of Medicine

Doctorate (PhD in Medicine)

Specialist (Fellow of College)

Other

If other, specify

For pharmacists only:

Bachelor of Pharmacy

Master of Pharmacy

Doctorate (PhD in Pharmacy)

Other

If other, specify

For nurses only:

Diploma in Nursing

$\mathrm{O}$

Bachelor in Nursing

O

Master of Nursing

O

Doctorate or PhD in Nursing

Other

If other, specify

\section{What is your field of practice?}

Public: Primary or community health centre

Public: District hospital

Public: Regional hospital

Public: Tertiary hospital

Private: Community

Private: Hospital

Academia

$\mathrm{O}$

○

$\bigcirc$

○

Other

Ifother, specify

If you are specialising, please state your area of specialisation and year obtained?

\section{Where do you practice?}

Urban area

O

Peri-urban area

O

Rural area

In which province do you practice?

Gauteng

North West

$\begin{array}{lcll}\text { KwaZulu-Natal } & \bigcirc & \text { Eastern Cape } & \bigcirc \\ \text { Limpopo } & \bigcirc & \text { Free State } & \bigcirc \\ \text { Mpumalanga } & \bigcirc & \text { Northern Cape } & \bigcirc \\ \text { Western Cape } & \bigcirc & & \end{array}$

\section{Section 2: Knowledge}

Would you consider antimicrobial resistance as a serious problem?

Please select your appropriate response for each item:

$$
\begin{array}{crr}
\begin{array}{c}
\text { Strongly Agree } \\
\text { agree }
\end{array} & \text { Neutral Disagree } & \begin{array}{l}
\text { Strongly } \\
\text { disagree }
\end{array}
\end{array}
$$

$\begin{array}{llllll}\text { Globally } & 0 & 0 & 0 & 0 & 0 \\ \begin{array}{l}\text { In South } \\ \text { Africa }\end{array} & 0 & 0 & 0 & 0 & 0 \\ \begin{array}{l}\text { In your } \\ \text { hospital or } \\ \text { practice }\end{array} & 0 & 0 & 0 & 0 & 0\end{array}$

How confident are you on your knowledge of antimicrobials, antimicrobial resistance and antimicrobial stewardship? (Rate yourself on a scale of 1 to 5 , with 1 being least confident and 5 being very confident)

$\begin{array}{lccccc}\text { Antimicrobials } & 1 & 2 & 3 & 4 & 5 \\ \begin{array}{l}\text { Antimicrobial } \\ \text { resistance }\end{array} & 0 & 0 & 0 & 0 & 0 \\ \begin{array}{l}\text { Antimicrobial } \\ \text { stewardship }\end{array} & 0 & 0 & 0 & 0 & 0\end{array}$

Are antimicrobial drugs effective in treating acute viral infections?

Yes $O$ No

Common colds caused are caused by:

Viruses $\mathrm{O}$

Bacteria $O$

Please select the factors you believe to be the most contributory towards antimicrobial resistance:

Overusage of antimicrobials by prescriptions

Overusage of antimicrobials without prescriptions

Errors in medical prescriptions (dose, duration of use, choice)

Non-compliance of patients with prescribed treatment

$\bigcirc \quad$ Inadequate hand washing

O Lack of immunisation campaigns

$\bigcirc \quad$ Lack of new antimicrobial drugs

O Use of antimicrobials as growth promoters in animals

○ Patient pressure for antimicrobial prescriptions 
Which of the following sources do you refer to for information on appropriate usage of antimicrobials? Please select your appropriate choice and rate on a scale of 1 to 5 ( $1=$ lowest preference and $5=$ highest preference):

$\begin{array}{lccccc} & 1 & 2 & 3 & 4 & 5 \\ \begin{array}{l}\text { Information from senior } \\ \text { experienced colleagues }\end{array} & 0 & 0 & 0 & 0 & 0 \\ \begin{array}{l}\text { South African Medicines } \\ \text { Formulary }\end{array} & 0 & 0 & 0 & 0 & 0 \\ \begin{array}{l}\text { The Merck Manual } \\ \text { Medical journals }\end{array} & 0 & 0 & 0 & 0 & 0 \\ \begin{array}{l}\text { Medical websites } \\ \text { Standard Treatment }\end{array} & 0 & 0 & 0 & 0 & 0 \\ \begin{array}{l}\text { Guidelines } \\ \text { International guidelines }\end{array} & 0 & 0 & 0 & 0 & 0 \\ \text { (e.g. Professional society } & & & & & 0 \\ \text { guidelines) } & 0 & 0 & 0 & 0 & 0\end{array}$

Please assess your levels of confidence in the following areas when prescribing antimicrobials?

( 1 = very confident, 2 = confident, $3=$ unsure, 4 = unconfident,

$5=$ very unconfident and $6=$ not applicable)

Making an accurate diagnosis $\begin{array}{llllll}1 & 2 & 3 & 4 & 5 & 6\end{array}$ of the infection

Decision not to prescribe antimicrobial when patient has a fever with no serious criteria

and you are not sure of the diagnosis

Selecting the correct antimicrobial

Selecting the correct dosage for the antimicrobial

Selecting the correct interval for the antimicrobial

Selecting the correct duration for the antimicrobial

Using combination therapy if necessary

Interpreting microbiological laboratory results

When to stop or streamline the antimicrobial therapy according to clinical evaluations and investigations

Selecting between an intravenous or oral antimicrobial
Do you think there are risks associated with irrational use of antimicrobials?

Yes $\mathrm{O}$

No $\mathrm{O}$

If you answered 'Yes', please list the risks.

Do you think restricting antimicrobial usage is necessary to reduce antimicrobial resistance?

Yes $\mathrm{O}$

No $\mathrm{O}$

Have you attended any workshops or had training on antimicrobials and antimicrobial stewardship?

Yes $\mathrm{No} \mathrm{O}$

If you selected 'Yes', kindly state when you attended the workshops or training.

Would you like more education and training on antimicrobial use, antimicrobial resistance and antimicrobial stewardship?

Yes $\mathrm{O}$

No $\mathrm{O}$

Please list the three most resistant bacteria you are aware of (with 1 being the most resistant and 3 being the least resistant):

1.

2.

What percentage of clinical antimicrobial use is unnecessary or inappropriate in South Africa?

B Between $1 \%$ and $20 \%$

O Between $21 \%$ and $40 \%$

○ Between $41 \%$ and $60 \%$

○ Between $61 \%$ and $80 \%$

O Between $81 \%$ and $100 \%$

\section{Section 3: Attitudes}

Antimicrobials are safe drugs that can be commonly prescribed?

Yes $\mathrm{O}$

No $\mathrm{O}$

Prescribing antimicrobials to a patient who does not really need them may ultimately have a negative impact on their health. Please choose one option from the list:

Strongly agree $\bigcirc$

Agree $O$

Neutral $\quad 0$

Disagree $\bigcirc$

Strongly disagree $\bigcirc$ 
In your opinion, do you think the problem of antimicrobial resistance is getting better or worse?

Better $\bigcirc \quad$ Worse $\mathrm{O}$

What do you think are the important strategies to combat antimicrobial resistance?

Select the most appropriate choices:

Educational campaigns

Use of therapeutic guidelines

Vaccination campaigns

Improved infection control

Reducing antimicrobial use in agriculture and animals

Better control on antimicrobial sales

Other

If other, specify:

Do you believe a patient skipping or missing one or two doses of antimicrobials contributes to the development of antimicrobial resistance?

No $\mathrm{O}$

Do you believe that new classes of antimicrobials will be developed in the next $5-10$ years?

Yes

No $\mathrm{O}$

Do you believe that you may personally be contributing towards antimicrobial resistance?

Yes $\mathrm{O}$

No $\mathrm{O}$

\section{Section 4: Practice}

For pharmacists only: In addition to your Bachelor of Pharmacy degree, do you possess the Section 22A (15) permit allowing you to prescribe for primary care drug treatment?

Yes $\mathrm{O}$

No O

For nurses only: Do you possess a concession permit in terms of Section 22A (12) from Medicines and Substances Control Act of 1965 and Section 38A of the Nursing act of 1978?

Yes $\mathrm{O}$

No $O$

Do you prescribe antimicrobial drugs to your patients?

Yes $\mathrm{O}$

No $\mathrm{O}$

Not applicable

Please select the average number of patients to whom you prescribe antimicrobials per day?

Not applicable $\quad \mathrm{O}$

Less than 5

Between 6 and 10
Between 11 and $20 \quad 0$

Between 21 and $30 \quad \bigcirc$

Between 31 and 40

Greater than 40

Do you prescribe antimicrobials empirically (based on observation and experience)?

Yes $\mathrm{O}$

No $\mathrm{O}$

Not applicable

Before initiating antimicrobial therapy, do you send samples for microbiology testing to inform the need for and/or choice of antimicrobial therapy?

Yes $\mathrm{O}$

No $\mathrm{O}$

Not applicable

Do you possess the latest South African Standard Treatment Guidelines?

Yes $\mathrm{O}$

No

How often do you use the antimicrobial treatment guidelines when deciding upon antimicrobials for a patient?

$\begin{array}{llll}\text { Always } & \bigcirc & \text { Sometimes } & \bigcirc \\ \text { Never } & \bigcirc & \text { Not applicable } & \bigcirc\end{array}$

Which three antimicrobials do you prescribe the most (if applicable)?

1.

2.

3.

Have you changed your prescribing behaviour in light of antimicrobial resistance in the past 5 years?

Yes O

No $\mathrm{O}$

Not applicable

If 'Yes', how?

What advice do you impart to patients on antimicrobial usage?

$\bigcirc$ The patient must complete the full course of antimicrobials for the recommended duration.

O The patient must take the antimicrobials at the correct time intervals.

$\bigcirc$ The patient should never share antimicrobial treatment with anyone.

$\bigcirc$ The patient must not stop treatment even if they are feeling better after a few doses.

O The patient must save the remaining antimicrobials for the next time they are unwell.

$\bigcirc$ The patient must dispose of remaining antimicrobials appropriately. 


\section{Antimicrobial treatment}

For doctors only:

Please provide the required information in the table below on antimicrobial treatment.

\begin{tabular}{|c|c|c|c|c|}
\hline \multirow[t]{2}{*}{ Condition } & \multicolumn{2}{|c|}{$\begin{array}{c}\text { Laboratory culture (select appropriate column - } \\
\text { Yes or No) }\end{array}$} & \multirow[t]{2}{*}{ Choice of antimicrobial } & \multirow[t]{2}{*}{$\begin{array}{c}\text { Adjunct or other drug } \\
\text { treatment }\end{array}$} \\
\hline & Always - A & On treatment failure - B & & \\
\hline \multicolumn{5}{|l|}{ Nasopharyngitis } \\
\hline \multicolumn{5}{|c|}{ Acute otitis media } \\
\hline \multicolumn{5}{|l|}{ Acute sinusitis } \\
\hline \multicolumn{5}{|l|}{ Bronchitis } \\
\hline \multicolumn{5}{|l|}{ Pneumonia } \\
\hline \multicolumn{5}{|l|}{ Cystitis } \\
\hline Pyelonephritis & & & & \\
\hline
\end{tabular}

For pharmacists only:

Please recommend which antimicrobial drugs you are authorised to prescribe for the following conditions (if applicable).

\begin{tabular}{|c|c|}
\hline & Recommended treatment \\
\hline \multicolumn{2}{|l|}{ Acute diarrhoea in adults } \\
\hline \multicolumn{2}{|l|}{ Chronic diarrhoea in adults } \\
\hline \multicolumn{2}{|l|}{ Acne vulgaris of skin } \\
\hline \multicolumn{2}{|l|}{ Urinary tract infections: } \\
\hline \multicolumn{2}{|l|}{ Uncomplicated cystitis in adults } \\
\hline \multicolumn{2}{|l|}{ Complicated cystitis in adults } \\
\hline \multicolumn{2}{|l|}{ Complicated cystitis in pregnant women } \\
\hline \multicolumn{2}{|l|}{ Respiratory conditions: } \\
\hline \multicolumn{2}{|l|}{ Acute bronchitis in adults and adolescents } \\
\hline \multicolumn{2}{|l|}{ Pneumonia uncomplicated (excludes paediatric and over 65 years) } \\
\hline \multicolumn{2}{|l|}{ Eye infections: } \\
\hline \multicolumn{2}{|l|}{ Bacterial eye infections, conjunctivitis (excludes newborn) } \\
\hline \multicolumn{2}{|l|}{ Ear, nose and throat conditions: } \\
\hline \multicolumn{2}{|l|}{ Otitis externa } \\
\hline \multicolumn{2}{|l|}{ Otitis media acute } \\
\hline \multicolumn{2}{|l|}{ Sinusitis, acute, bacterial } \\
\hline Tonsillitis and pharyngitis & \\
\hline
\end{tabular}

For nurses only:

Please recommend which antimicrobial drugs you are authorised to prescribe for the following conditions (if applicable).

\begin{tabular}{|l|l|}
\hline Condition: & Recommended treatment \\
\hline Severe necrosing gingivitis & \\
\hline Tick bite fever & \\
\hline
\end{tabular}




\begin{tabular}{|l|l|}
\hline Acute meningitis & \\
\hline Conjunctivitis & \\
\hline Acute otitis media & \\
\hline Acute sinusitis & \\
\hline Bacterial tonsillitis & \\
\hline Acute bronchitis & \\
\hline Boil abscess & \\
\hline Urinary tract infection, uncomplicated & \\
\hline
\end{tabular}

Thank you for your valuable time in participating in this study. Your response will be invaluable towards optimising rational antimicrobial use and AMS.

Thank you for completing this survey.

Submit your survey. 